\title{
Influence of Deformation and Molybdenum Content on Acicular Ferrite Formation in Medium Carbon Steels
}

\author{
Carlos CAPDEVILA, Juan P. FERRER, Carlos GARCíA-MATEO, Francisca G. CABALLERO, Victor LÓPEZ and \\ Carlos GARCÍA DE ANDRÉS
}

MATERALIA Research Group, Department of Physical Metallurgy, Centro Nacional de Investigaciones Metalurgicas (CENIM), Consejo Superior de Investigaciones Científicas (CSIC), Avda. Gregorio del Amo, 8, 28040 Madrid, Spain.

E-mail:ccm@cenim.csic.es

(Received on February 2, 2006; accepted on March 14, 2006)

\begin{abstract}
The present work deals with the influence of deformation and molybdenum content on the subsequent austenite-to-acicular ferrite transformation during continuous cooling in medium carbon microalloyed steels. The results obtained demonstrate that higher deformation temperature induces a finer austenite grain size as a result of austenite recrystallisation processes during cooling down to austenite decomposition temperature. The higher the molybdenum content and severity of deformation are, the finer austenite grain is. Likewise, it was concluded that molybdenum suppress pearlitic microstructure, and clearly delay proeutectoid ferrite field to longer times. By contrast, acicular ferrite transformation is enhanced in molybdenum rich steel, which not only affect the volume fraction but also the morphology of acicular ferrite.
\end{abstract}

KEY WORDS: forging steel; acicular ferrite; phase transformation; molybdenum; continuous cooling diagrams.

\section{Introduction}

Acicular ferrite microstructure, which provides effective grain (structural) refinement, is one of the most desired microstructure that improves both strength and toughness. Recent experimental results ${ }^{1-3)}$ strongly indicate that a fine acicular ferrite microstructure can be obtained in medium carbon microalloyed forging steels. This subject represents a major and very exciting advance in the technology of steels. However, a deep understanding of the influences that the alloying elements have on the final microstructure should be reached to produce this kind of steels directly by industrial thermomechanical processes. Although the role of elements such as manganese has been thoroughly reported in literature, ${ }^{4,5)}$ the role of molybdenum, on the counterpart, is a subject that not so much attention on literature has been paid.

There is evidence to show that in many cases, acicular ferrite is in effect bainite, which nucleates intragranularly on inclusions. For example, the transformation of acicular ferrite occurs below the Bs temperature, ${ }^{6)}$ the transformation exhibits an incomplete-reaction phenomenon, ${ }^{7)}$ the growth of acicular ferrite causes a shape deformation which is characterised as an invariant plane strain with a large shear component, leading to a stored energy of about 400 $\mathrm{J} \mathrm{mol}^{-1}$, which is similar to that of bainite. ${ }^{8)}$ Like bainite, the acicular ferrite always has a well-defined crystallographic orientation relationship with the austenite grain in which it grows, and indeed, is restricted to grow in that grain because the coordinated motion of atoms cannot be sustained across an arbitrary grain boundary. ${ }^{7,8)}$ There is no partitioning of substitutional alloying elements. ${ }^{8)}$ Thus, it is expected that the transformation to acicular ferrite, as that of bainite, can be affected by elastic stress ${ }^{9)}$ and by the plastic deformation of austenite.

Therefore, the main aim of this work is two fold: Firstly, to clarify the role of the severe plastic deformation of austenite during forging process on the subsequent transformation of austenite-to-acicular ferrite, and secondly, to clarify the role of molybdenum on such transformation.

\section{Materials and Experimental Procedure}

The chemical composition of the two forging steels studied is presented in Table 1. The material was supplied in the form of $50 \mathrm{~mm}$ square bars, obtained by conventional casting to an square ingot ( $2500 \mathrm{~kg}$ weight) and hot rolling to bar. Cylindrical dilatometric test pieces of $2 \mathrm{~mm}$ diameter and $12 \mathrm{~mm}$ length were machined longitudinally to the rolling direction of the bar.

An Adamel Lhomargy DT1000 high resolution dilatometer has been used to determine the CCT diagrams of this steel. The dimensional variations of the specimen are transmitted via an amorphous silica pushrod. These variations are measured by a LVDT sensor in a gas-tight enclosure en-

Table 1. Chemical composition (mass\%).

\begin{tabular}{|c|c|c|c|c|c|c|c|c|c|c|}
\hline & $\mathrm{C}$ & $\mathrm{Mn}$ & $\mathrm{Si}$ & $\mathrm{Cr}$ & $\mathrm{Ni}$ & $\mathrm{Mo}$ & $\mathrm{V}$ & $\mathrm{Al}$ & $\mathrm{Ti}$ & $\mathrm{N}(\mathrm{ppm})$ \\
\hline Steel A & 0.36 & 1.44 & 0.63 & 0.17 & 0.13 & 0.02 & 0.09 & 0.020 & 0.022 & 96 \\
\hline Steel B & 0.38 & 1.44 & 0.62 & 0.07 & 0.04 & 0.16 & 0.10 & 0.026 & 0.016 & 122 \\
\hline
\end{tabular}


abling testing under vacuum or in an inert atmosphere. The temperature is measured with a $0.1 \mathrm{~mm}$ diameter ChromelAlumel (Type K) thermocouple welded to the specimen. Cooling is carried out by blowing a jet of helium gas directly onto the specimen surface. The helium flow rate during cooling is controlled by a proportional servovalve. The excellent efficiency of heat transmission and the very low thermal inertia of the system ensure that the heating and cooling rates ranging from $0.003 \mathrm{~K} / \mathrm{s}$ to approximately $200 \mathrm{~K} / \mathrm{s}$ remain constant.

Thermomechanical cycles were simulated in a Bähr DIL $805 \mathrm{~A} / \mathrm{D}$ deformation dilatometer. To simplify the experiment, two of the three thermal parameters conditioning the state of austenitisation were kept constant in the heating cycle: the heating rate, $10^{\circ} \mathrm{C} / \mathrm{s}$, and the holding time, $180 \mathrm{~s}$. Thus, the austenitisation temperature is the only thermal parameter capable of modifying and predetermining the state of austenitisation of this steel. Specimens were polished and etched in the usual way for metallographic examination. The microstructure was examined by light optical microscopy and prior austenite grain size (PAGS) was measured according to Underwood's intersection method. ${ }^{10)}$

\section{Results and Discussion}

\subsection{Effect of Molybdenum on Non-isothermal and Isothermal Acicular Ferrite Microstructure}

It is generally accepted that austenite decomposition is delayed in molybdenum containing steels leading to an increase in hardenability. ${ }^{5)}$ In the present work, the influence of molybdenum on the evolution of the austenite-to-acicular ferrite transformation as well as on the morphology of this phase has been investigated.

The CCT diagrams of the two steels studied in this work are presented in Figs. 1 and 2. Figure 1 shows that the nonisothermal austenite-to-acicular ferrite transformation in steel A occurs at cooling rates ranging from 20 to $0.5^{\circ} \mathrm{C}$ $\mathrm{s}^{-1}$. The allotriomorphic ferrite formation is avoided cooling down at a rate higher than $20^{\circ} \mathrm{C} \mathrm{s}^{-1}$. Pearlite formation is suppressed if the cooling is carried out at a rate of $7^{\circ} \mathrm{C}$ $\mathrm{s}^{-1}$ or higher. The micrograph in Fig. 3(a) shows that at a cooling rate of $10^{\circ} \mathrm{C} \mathrm{s}^{-1}$ a fine layer of allotriomorphic ferrite which represents approximately the $5 \%$ of the microstructure covers the most part of the prior austenite grain

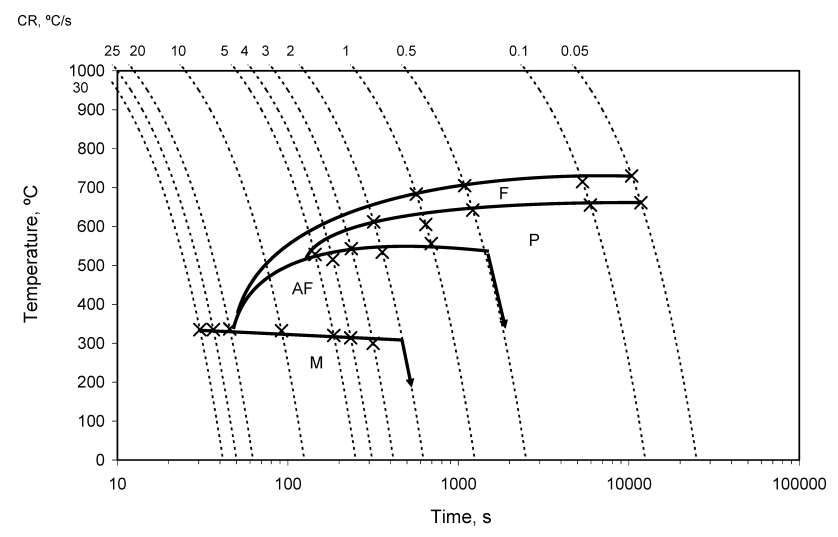

Fig. 1. CCT diagram for the steel $A$, after an austenitisation at $1250^{\circ} \mathrm{C}$. $(\mathrm{F}=$ Allotriomorphic Ferrite, $\mathrm{P}=$ Pearlite, $\mathrm{AF}=$ Acicular Ferrite, $\mathrm{M}=$ Martensite). boundaries. The intragranular formation of ferrite leads to a mainly acicular ferrite microstructure for steel A cooled at the above mentioned cooling rate. Nevertheless, the decomposition of austenite does not complete before the martensite start temperature is reached, which causes the apparition of martensite at the later stages of the cooling. By contrast, at a cooling rate of $6^{\circ} \mathrm{C} \mathrm{s}^{-1}$ (Fig. 3(b)), a reduction in the final amount of martensite is observed, the volume fraction of allotriomorphic ferrite increases to $10 \%$, and a $2 \%$

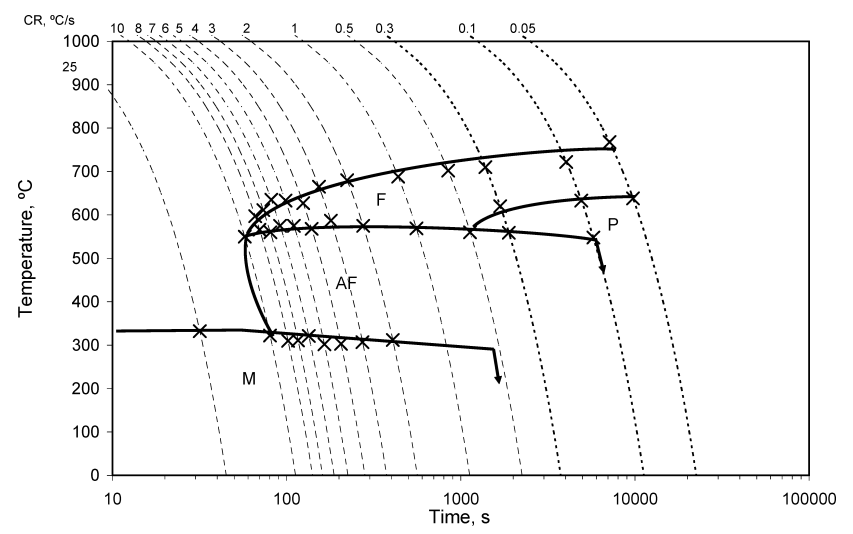

Fig. 2. CCT diagram for the steel $B$, after an austenitization at $1125^{\circ} \mathrm{C}$. $(\mathrm{F}=$ Allotriomorphic Ferrite, $\mathrm{P}=$ Pearlite, $\mathrm{AF}=$ Acicular Ferrite, $\mathrm{M}=$ Martensite).
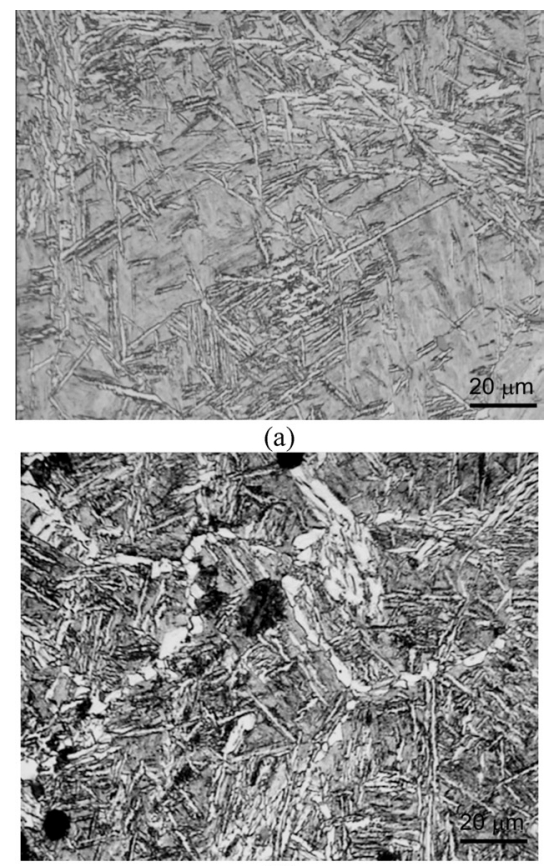

(b)

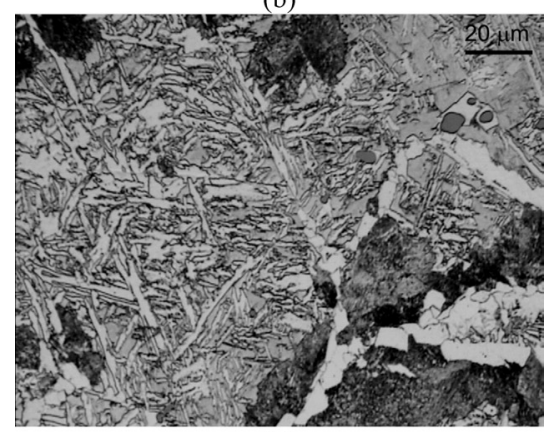

(c)

Fig. 3. Microstructures obtained in steel $\mathrm{A}$ after the continuous cooling at (a) $10^{\circ} \mathrm{C} \mathrm{s}^{-1}$, (b) $6^{\circ} \mathrm{C} \mathrm{s}^{-1}$ and (c) $3{ }^{\circ} \mathrm{C} \mathrm{s}^{-1}$. 
of pearlite is also present in the final microstructure. At a cooling rate of $3^{\circ} \mathrm{C} \mathrm{s}^{-1}$ (Fig. 3(c)), significant amounts of allotriomorphic ferrite and pearlite are present in the final microstructure. Cooling rates lower than $1^{\circ} \mathrm{C} \mathrm{s}^{-1}$ would promote the formation of a mixture of allotriomorphic ferrite and pearlite as the main microstructural components.

The formation of an allotriomorphic ferrite layer on the previous austenite grain boundaries is well known ${ }^{11)}$ to inhibit the formation of bainite and contributes indirectly to the nucleation of AF. However, the steel A presents a high tendency to form an AF microstructure instead of bainite, even in the absence of this ferrite layer. By cooling at a rate between 10 and $2^{\circ} \mathrm{C} \mathrm{s}^{-1}$, the final microstructure is mainly AF.

The addition of Mo to the steel modifies the CCT curves. In comparison with the diagram for steel $\mathrm{A}$ in Fig. 1, the pearlite region in the CCT diagram of steel B (Fig. 2) is displaced to longer times. The region corresponding to the acicular ferrite transformation is expanded to lower cooling rates and slightly higher temperatures. It is also observed that, like in steel A, the diminution of the allotriomorphic ferrite is not accompanied by the transition from acicular ferrite to bainite formation. As a result, the range of cooling rates leading to the formation of acicular ferrite as the predominant microstructural constituent in the Mo containing steel ranges now from 6 to $0.3^{\circ} \mathrm{C} \mathrm{s}^{-1}$. The produced microstructures for different cooling rates are shown in Fig. 4. The differences between steels A and B can be understood comparing the micrographs in Fig. 3 and Fig. 4. It can be seen that a $2 \%$ of pearlite is found in steel A upon cooling at $6^{\circ} \mathrm{C} \mathrm{s}^{-1}$ but it is not distinguishable in steel $\mathrm{B}$ even at a much lower cooling rate of $0.5^{\circ} \mathrm{Cs}^{-1}$. On the other hand, cooling rates higher than $6^{\circ} \mathrm{C} \mathrm{s}^{-1}$ applied to steel $\mathrm{B}$ produce significant amounts of martensite. According to the CCT diagrams in Figs. 1 and 2, Mo does not seem to have a large effect on the Ms temperature. However, when acicular ferrite forms, the presence of Mo in the steel enhances the apparition of martensite in the final microstructure, even for cooling rates as low as $0.6^{\circ} \mathrm{C} \mathrm{s}^{-1}$. This is probably due to the influence this element has on the transformation kinetics and on the hardenability. In the absence of this element (steel A) martensite formation requires cooling rates higher than $2^{\circ} \mathrm{C} \mathrm{s}^{-1}$.

Isothermal treatments in the range $500-400^{\circ} \mathrm{C}$ and hold there to complete the transformation have also been carried out to investigate comparatively the behaviour of both steels and the effect of the Mo on the acicular ferrite microstructure. The microstructural compositions obtained are shown in Table 2 for both steels. It can be seen that, for temperatures lower than about $450^{\circ} \mathrm{C}$, the microstructure is mainly acicular ferrite. Above this temperature, different mixtures of ferrite, pearlite and acicular ferrite form. The final microstructures obtained for a holding time of $20 \mathrm{~min}$ at $450^{\circ} \mathrm{C}$ are shown in Fig. 5 for both steels. It can clearly be seen in the micrographs that Mo not only affects the isothermal austenite decomposition but also modifies the morphology of the transformation product. Steel A exhibits a microstructure after this treatment formed by the well known randomly oriented ferrite plates while steel B develops packets formed by different parallel sub-units.

It was observed in the partially transformed microstruc-

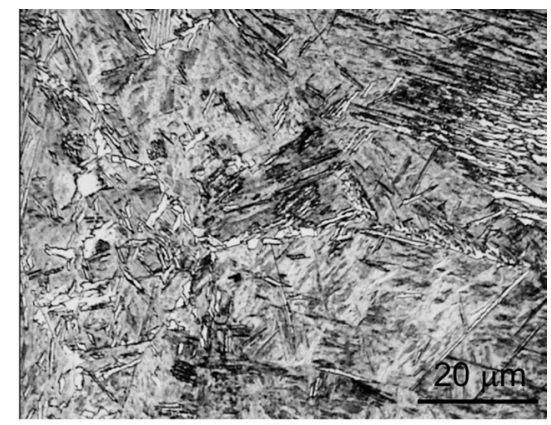

(a)

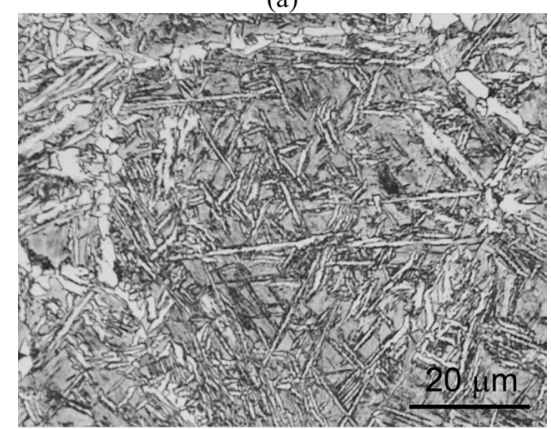

(b)

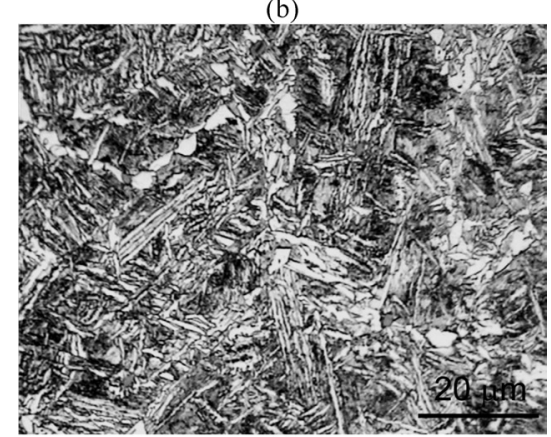

(c)

Fig. 4. Microstructures obtained in steel $\mathrm{B}$ after continuous cooling at (a) $6^{\circ} \mathrm{C} \mathrm{s}^{-1}$, (b) $3^{\circ} \mathrm{C} \mathrm{s}^{-1}$ and (c) $0.75^{\circ} \mathrm{C} \mathrm{s}^{-1}$.

Table 2. Constituents of the final microstructures after isothermal heat treatments.

\begin{tabular}{|c|c|c|}
\hline \multirow[t]{2}{*}{ Temperature $\left({ }^{\circ} \mathrm{C}\right)$} & \multicolumn{2}{|c|}{ Microstructure } \\
\hline & Steel A & Steel B \\
\hline 500 & $\mathrm{P}, \mathrm{AF}, \mathrm{F}$ & $\mathrm{AF}$ (SPP), $\mathrm{P}$ \\
\hline 450 & $\mathrm{AF}$ & AF (SPP) \\
\hline 400 & AF (SPP) & AF (SPP) \\
\hline
\end{tabular}
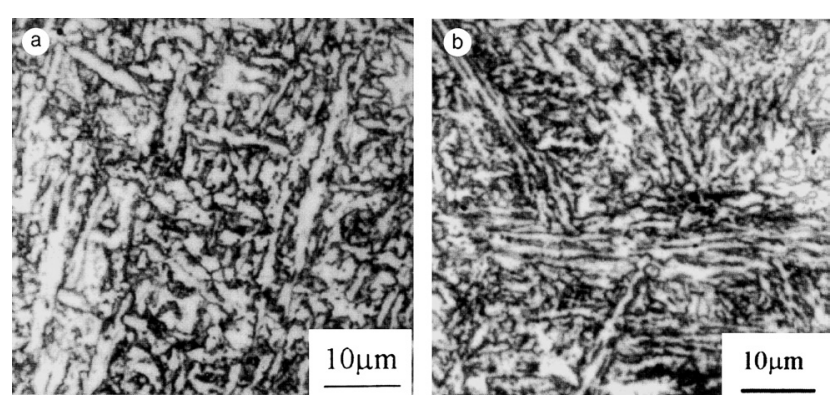

Fig. 5. Final microstructures obtained by isothermal treatment during $20 \mathrm{~min}$ at $450^{\circ} \mathrm{C}$ (a) steel A and (b) steel B. 
tures produced by interrupted isothermal tests that primary acicular ferrite plates in steel A nucleate on the second phase particles. Theses have been identified as being $\mathrm{MnS}$ particles covered by a shell of CuS. This shell seems to be favourable in terms of acicular ferrite formation, as discussed by Madariaga and Guitierrez. ${ }^{12)}$ The same type of particles also produces AF nucleation in steel $\mathrm{B}^{13)}$ Nevertheless, it has been shown that the transformation can progress in two different ways, through the autocathalityc nucleation of new plates in different orientations to the primary ones (hereafter called upper acicular ferrite), or by the formation of sheave composed by subunits parallel to them (hereafter called lower acicular ferrite, see Fig. 5(b)). ${ }^{14)}$ In the first case, the result is the typical interlocking microstructure of acicular ferrite that can be seen in Fig. 5(a) for the steel A at $450^{\circ} \mathrm{C}$. Steel B behaves according to the second type of morphology (Fig. 5(b)).

This transition between both types of transformation relates to the carbon mobility which is expected to depend not only on the treatment temperature but also on the steel composition (Fig. 6). As can be seen in Fig. 6(c), the Mo containing steel presents an evolution of the transformation at $450^{\circ} \mathrm{C}$ similar to that exhibited by the steel $\mathrm{A}$ at $400^{\circ} \mathrm{C}$ (Fig. 6(b)). According to the present results, it seems that the addition of Mo has raised the temperature of transition between upper and lower acicular ferrite and consequently the temperature of formation of sheaves instead of plates.

\subsection{Effect of Forging Temperature on Acicular Ferrite Formation}

The effect of forging temperature was studied by means of thermomechanical cycles as the ones presented in Fig. 7. Since dynamic recrystallisation is expected during deformation, and in order to avoid very coarse grain sizes, rapid cooling is performed from deformation to $1000^{\circ} \mathrm{C}$. Hence, continuous cooling cycles at different rates to room temperature were performed.

In order to avoid the effect of grain size, the same PAGS in both steels has been considered. In this sense, a value of $63 \pm 7 \mu \mathrm{m}$ was measured after holding at $1250^{\circ} \mathrm{C}$ for $180 \mathrm{~s}$ in steel $\mathrm{A}$, and a value of $66 \pm 7 \mu \mathrm{m}$ was obtained after holding at $1125^{\circ} \mathrm{C}$ for $180 \mathrm{~s}$ in steel B. Deformation conditions are listed in Table 3.

The values of recrystallised grain sizes (RAGS) are listed in Table 3. It is clear from the data that considerably grain refinement is obtained after deformation. Likewise, since deformation temperature for steel B is smaller, the combined effect of higher nucleation of recrystallised austenite grains in the deformed matrix, together with a slow grain growth process after recrystallisation, can explain the finer grain size obtained.

Figures 8 and 9 show a comparison between the CCT diagrams in both steels with and without deformation. It is clear that hardenability is decreased in both steel under all deformation conditions. In this sense, allotriomorphic ferrite and pearlite are enhanced. Likewise, acicular ferrite is also enhanced in detriment of martensite. This is especially significant in Mo-rich steel as it can be seen in the CCT diagram of steel B (Fig. 9).

The separate effect of deformation and deformation rate has been analysed in steel A. As degree of deformation at
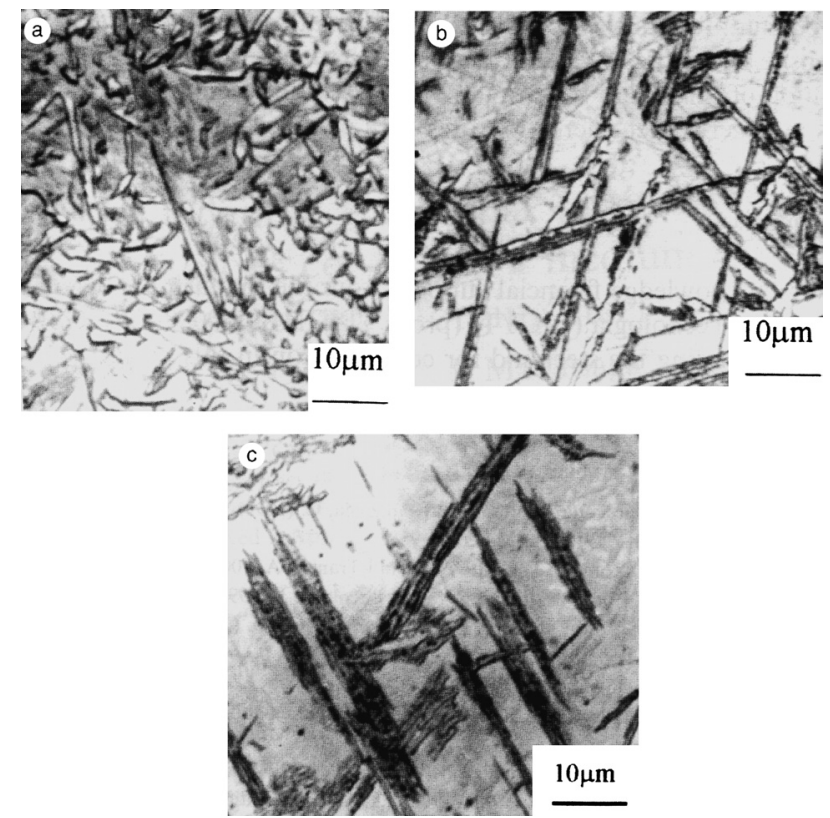

Fig. 6. Optical micrographs (a) steel A held during $10 \mathrm{~s}$ at $450^{\circ} \mathrm{C}$, (b) steel A held during $20 \mathrm{~s}$ at $400^{\circ} \mathrm{C}$ and (c) steel $\mathrm{B}$ held during $20 \mathrm{~s}$ at $450^{\circ} \mathrm{C}$ followed in all the cases by water quenching.

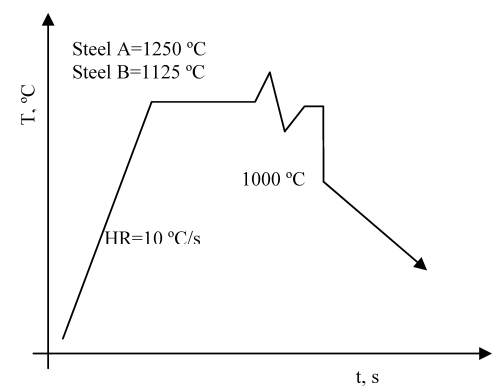

Fig. 7. Scheme of thermomechanical cycle applied.

Table 3. Deformation parameters.

\begin{tabular}{|c|c|c|c|c|}
\hline Material & $\varepsilon$ & $\dot{\varepsilon}\left(\mathrm{s}^{-1}\right)$ & $\mathrm{T}\left({ }^{\circ} \mathrm{C}\right)$ & RAGS $(\mu \mathrm{m})$ \\
\hline & & & & \\
\hline Steel A_1 & 0.5 & 1 & 1250 & $48 \pm 7$ \\
\hline Steel A_2 & 1 & 1 & 1250 & $41 \pm 6$ \\
\hline Steel A_3 & 1 & 10 & 1250 & $38 \pm 2$ \\
\hline Steel B_1 & 1 & 10 & 1125 & $17 \pm 2$ \\
\hline
\end{tabular}

high temperature increases, a refinement of austenite grain is induced, and hence, hardenability is reduced. Therefore, allotriomorphic ferrite and pearlite are prone to be formed consuming most of the austenite volume before acicular ferrite transformation could take place. In this sense, it could be concluded that deformation at high temperature decrease the amount of acicular ferrite obtained in the microstructure comparing the same thermal cycle without deformation (Fig. 3 vs. Fig. 10). On the other hand, it is also worth noting that deformation rate does not affect significantly the transformation fronts in steel A, which is consis- 
tent with the idea that fully recrystallisation of austenite takes place before austenite decomposition starts.

Concerning steel $\mathrm{B}$, it is clear that deformation at high temperatures shifts the transformation fronts to smaller times because the lower hardenability caused by the decrease on austenite grain size after deformation. However, such decrease in hardenability is compensated by the increase due to the higher molybdenum content. However, the decrease of hardenability produced by deformation at high temperatures is compensated by the increase in Mo content. In this sense, meanwhile cooling an undeformed austenite at rates between 6 and $0.7^{\circ} \mathrm{C} / \mathrm{s}$ in steel $\mathrm{B}$ produce acicular ferrite as the major component, such window is shifted to

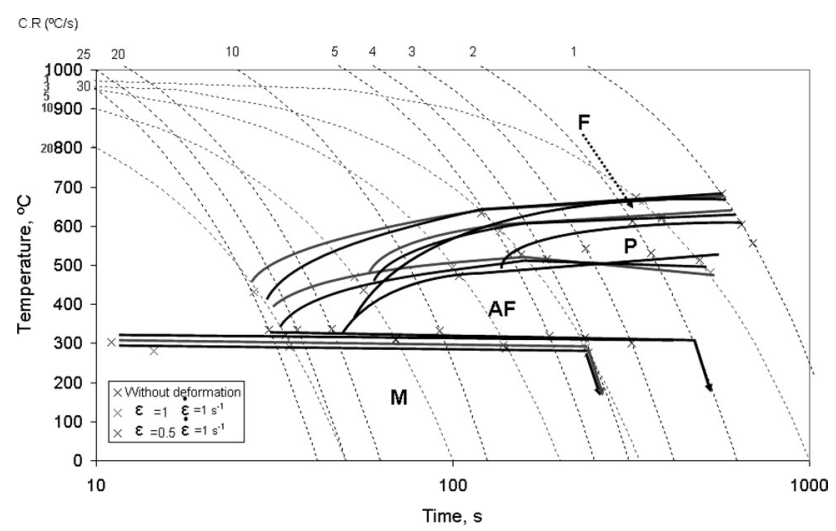

(a)

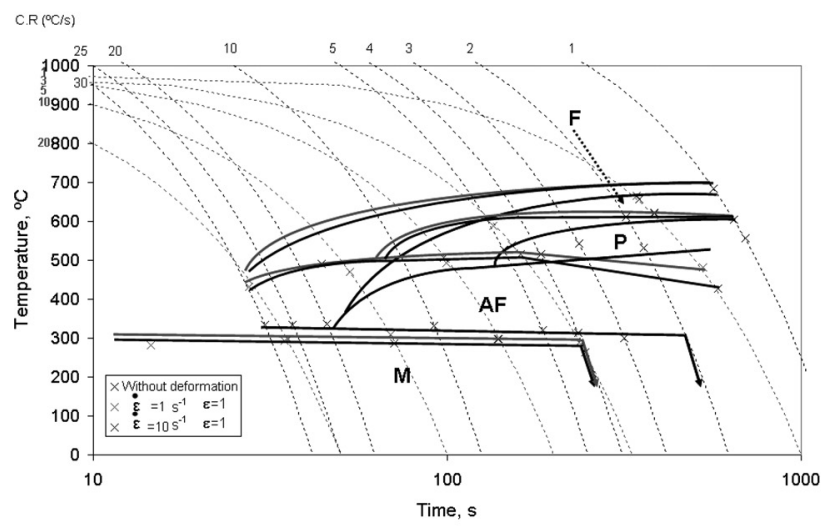

(b)

Fig. 8. Effect of (a) deformation and (b) deformation rate on CCT diagrams for steel A. cooling rates ranging from 10 to $4{ }^{\circ} \mathrm{C} / \mathrm{s}$ in deformed steel. Thus, acicular ferrite is enhanced in this steel as compared with undeformed steel (Fig. 4 vs. Fig. 11).

Finally, as a summary, the evolution of volume fraction of $\mathrm{AF}$ at cooling rate of $6^{\circ} \mathrm{C} / \mathrm{s}$ from an undeformed and deformed at high temperature austenite is listed in Table $\mathbf{4}$ for steels A and B. It is clear that as Mo content increases (steel
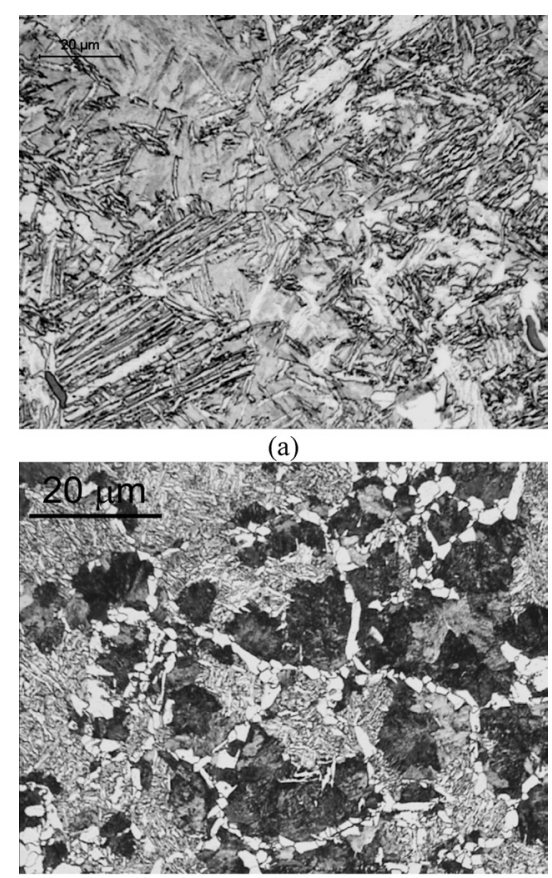

(b)

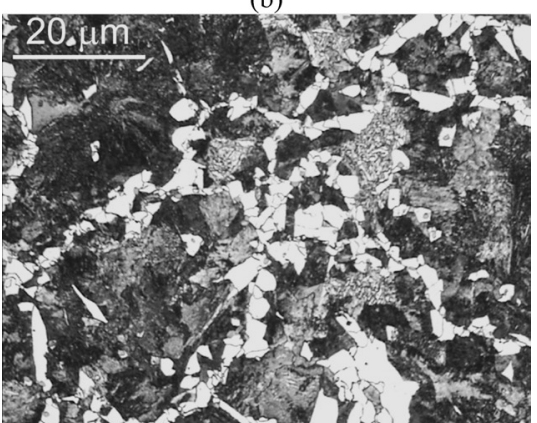

(c)

Fig. 10. Micrographs of deformed steel $\mathrm{A}(\varepsilon=1$ and $\dot{\varepsilon}=1)$, and cooled at (a) 10 , (b) 6 and (c) $3{ }^{\circ} \mathrm{C} / \mathrm{s}$.

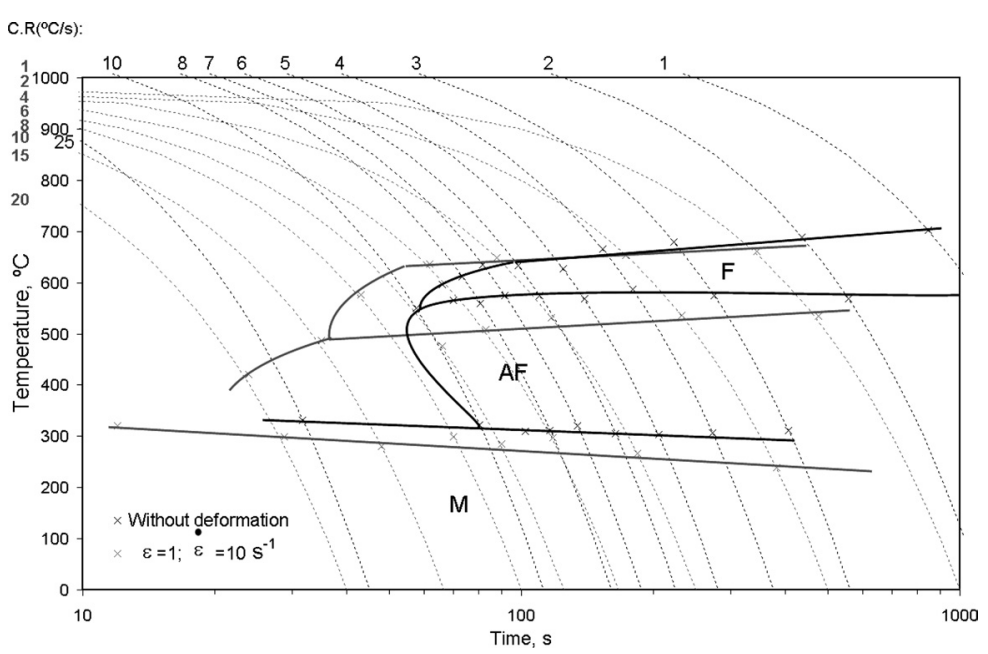

Fig. 9. Effect of deformation on CCT diagram for steel B. 


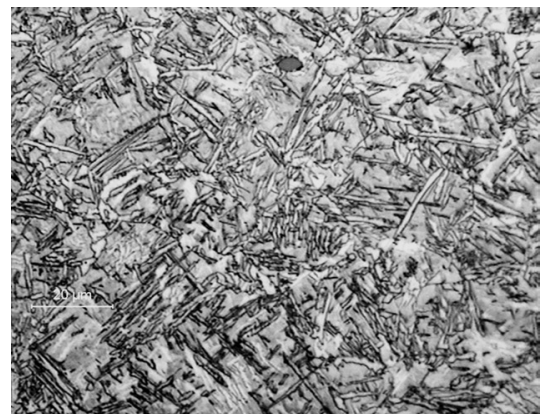

(a)

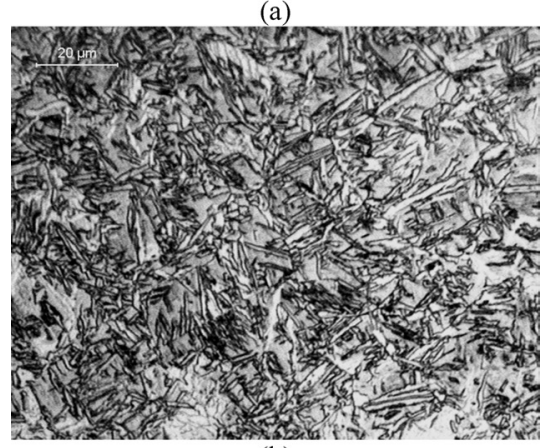

(b)

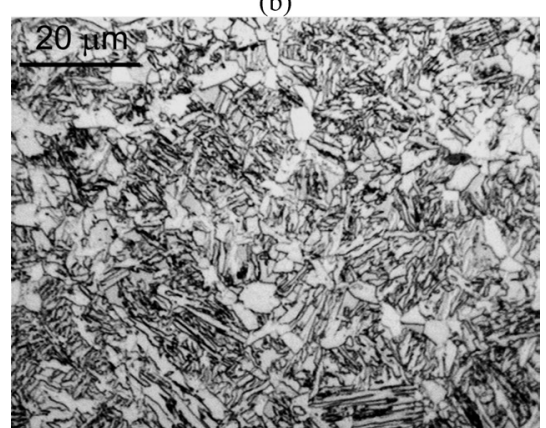

(c)

Fig. 11. Micrographs of deformed steel B and cooled at (a) 6 , (b) 4 and (c) $1{ }^{\circ} \mathrm{C} / \mathrm{s}$.

Table 4. Evolution of $\mathrm{AF}$ volume fraction obtained at $6^{\circ} \mathrm{C} / \mathrm{s}$ cooling rate.

\begin{tabular}{|c|c|c|}
\hline & $\begin{array}{c}\text { Undeformed } \\
\text { austenite }\end{array}$ & $\begin{array}{c}\text { Deformed } \\
\text { austenite }\end{array}$ \\
\hline Steel A & $80 \%$ & $48 \%$ \\
\hline Steel B & $21 \%$ & $65 \%$ \\
\hline
\end{tabular}

B vs. A) the volume fraction of AF decreases during continuous cooling from an undeformed austenite, since the volume fraction of martensite increases dramatically. However, the deformation induces a decrease in volume fraction of $\mathrm{AF}$ in steel A, but an increase in steel B due to the above mentioned balanced effect in hardenability between Mo content and the refinement of austenite grain size due to deformation.

\subsection{Effect of Low Deformation Temperature on Acic- ular Ferrite Formation}

In order to analyse the effect that unrecrystallised austenite has on acicular ferrite transformation, deformation at low temperatures has been performed. Figure 12 shows the thermomechanical cycle scheme for this processing.

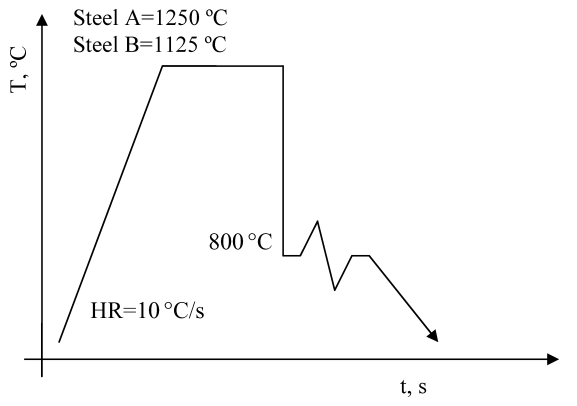

Fig. 12. Scheme of thermomechanical cycle applied.

Table 5. Deformation parameters for A and B steels. CR stands for the cooling rate after deformation.

\begin{tabular}{|c|c|c|}
\hline$\varepsilon$ & $\dot{\varepsilon}\left(\mathrm{s}^{-1}\right)$ & $\mathrm{CR}\left({ }^{\circ} \mathrm{C} / \mathrm{s}\right)$ \\
\hline 1 & 1 & 2 \\
\hline 1 & 1 & 5 \\
\hline 1 & 10 & 2 \\
\hline 1 & 10 & 5 \\
\hline
\end{tabular}

The deformation parameters are listed in Table 5. As a common behaviour between steels $\mathrm{A}$ and $\mathrm{B}$, outer part of the sample recrystallise meanwhile the centre remains unrecrystallised as it is schematically shown in Fig. 13(a). After austenite decomposition proceeds, it is clear the different microstructure observed between both areas of the sample. Meanwhile acicular ferrite/bainite microstructures are the main component in the outer part of the sample; allotriomorphic ferrite and pearlite are the major component of the microstructure in the centre (Figs. 13(b) and 13(c), respectively).

The result presented in Fig. 13 is consistent with the increasing of grain boundary nucleation sites in deformed austenite as compare with a coarser recrystallised grain. Likewise, it seems that increasing deformation promotes the formation of allotriomorphic ferrite even inside the austenite grain (shear bands) as it is shown in Fig. 14. This is consistent with previous works of De Ardo and co-workers. ${ }^{15)}$ This observation together with the fact that displacive transformations such as acicular ferrite are seriously impeded in a deformed austenite, ${ }^{16)}$ produce a significant decrease on acicular ferrite volume faction.

Although deformation at low temperatures seems to reduce the volume fraction of acicular ferrite formed, it was found that strain rate has a strong effect on acicular ferrite formation. The microstructure obtained at the same cooling rate and the same deformation level but two different strain rates was analysed. Figure 15 shows that the volume fraction of acicular ferrite seems to be increased for high strain rates as compared with lower ones. This is consistent with the increase of shear bands at high strain rates and hence intragranular nucleation sites increases. ${ }^{17)}$

\section{Conclusions}

(1) Molybdenum content not only affects the nonisothermal and isothermal austenite decomposition process- 


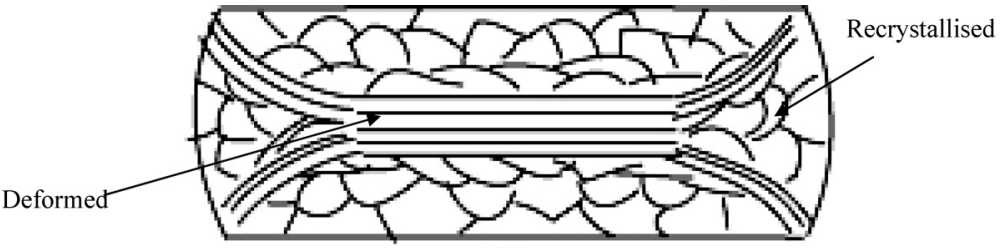

(a)

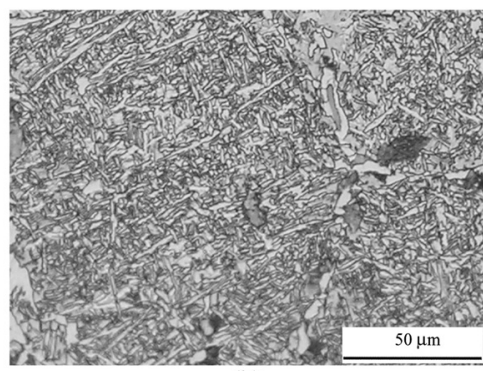

(b)

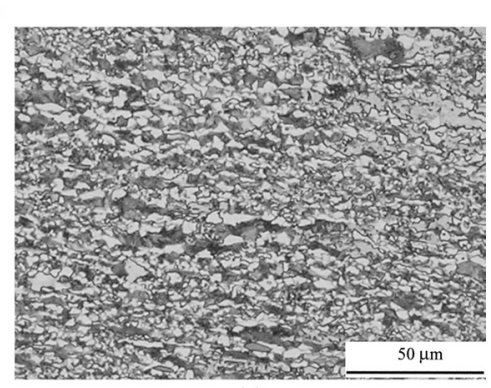

(c)
Fig. 13. (a) Scheme of prior austenite grain structure, (b) outer and (c) centre of steel A.

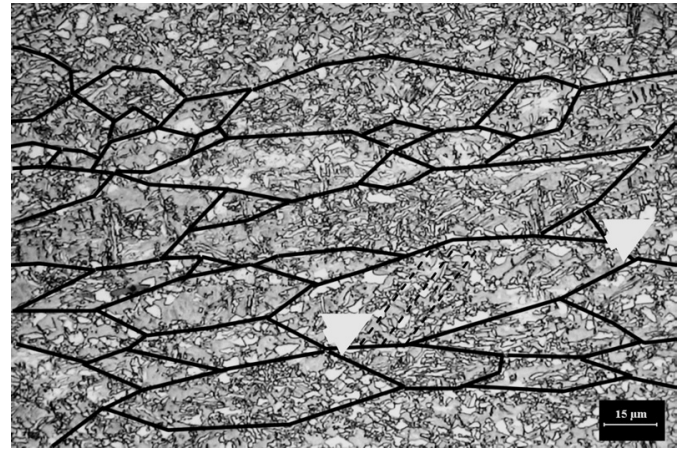

Fig. 14. Formation of intragranular proeutectoid ferrite in steel A (see arrows). Black solid lines indicate the prior deformed austenite grain. Dashed lines indicate shear bands.

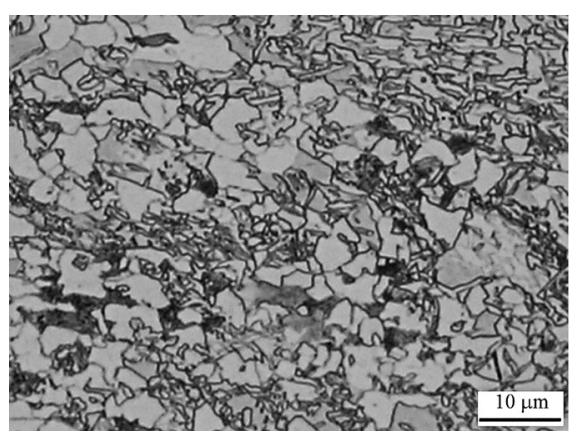

(a)

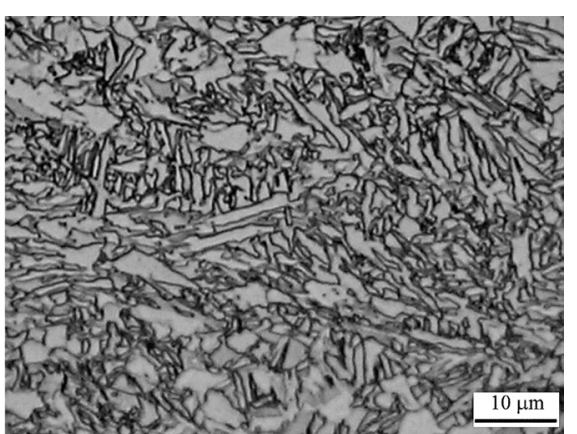

(b)

Fig. 15. Microstructure of steel $\mathrm{B}$ obtained after deformation at $\varepsilon=1$, and cooled at $2{ }^{\circ} \mathrm{C} / \mathrm{s}$ but deformed at (a) $1 \mathrm{~s}^{-1}$ and (b) $10 \mathrm{~s}^{-1}$ strain rates

es but also modifies the acicular ferrite morphology.

(2) Molybdenum increases the amount of martensite being present in the final microstructure. In Mo containing steel, the formation of this phase is the main variable limiting the design of useful cooling cycles in order to get microstructures with enhanced mechanical properties.

(3) Since finer austenite grain size after recrystallisation is obtained during forging, the hardenability decreases, increasing the amount of allotriomorphic ferrite and pearlite in detriment of acicular ferrite. However, the increase in hardenability due to Molybdenum addition can compensate such detrimental effect, and hence acicular ferrite is enhanced in the Molybdenum-rich forged steel.

(4) Deformation at low temperatures boost proeutectoid ferrite formation (allotriomorphic and idiomorphic ferrite) at both austenite grain boundaries and shear bands inside the austenite grains, which has a detrimental effect on acicular ferrite formation.

(5) The increase of strain rate seems to trigger acicular ferrite formation for the same deformation level and cooling conditions. This is consistent with the increase of shear bands and hence the density of intragranular nucleation sites.

\section{Acknowledgements}

The authors acknowledge financial support from
European Community and Spanish Ministerio de Educación y Ciencia (MEC) in the form of RFCS Project (RFS-CR-04030) and a Complementary Project (MAT24485-E). C. García-Mateo would like to thank to MEC for the financial support in the form of a Ramon y Cajal contract. J. P. Ferrer would also like to express his gratitude to MEC for the financial support in the form of a PhD Grant (FPI Program).

\section{REFERENCES}

1) C. García De Andrés, C. Capdevila, I. Madariaga and I. Gutierrez: Scr. Mater, 45 (2001), 709.

2) C. García De Andrés, C. Capdevila, F. G. Caballero and D. San Martín: J. Mater. Sci., 36 (2001), 565.

3) C. García De Andrés, C. Capdevila and F. G. Caballero: Proc. of European Conf. on Materials in Oceanic Environment. EUROMAT'98. Vol. II, L. Faria, Lisboa, (1998), 217.

4) K. R. Kinsman and H. I. Aaronson: Transformation and Hardenability in Steels, Climax Molybdenum Co, Ann Arbor, Michigan, (1967), 39.

5) H. W. Paxton and E. C. Bain: Alloying Elements In Steels, ASM, Metals Park, OH, (1966), 274.

6) S. S. Babu and H. K. D. H. Bhadeshia: Mater. Sci. Technol., 6 (1990), 1005.

7) H. K. D. H. Bhadeshia and J. W. Christian: Metall. Mater. Trans. A, 21A (1990), 767.

8) M. Strangwood: Ph. D. Thesis, University Of Cambridge, Cambridge, UK, (1987). 
9) S. S. Babu and H. K. D. H. Bhadeshia: Mater. Sci. Eng. A, 156 (1992), 1

10) G. F. Vander Voort: Metallography. Principles and Practice, McGraw-Hill Book Company, New York, (1984), 427.

11) R. A. Ricks, P. R. Howell and G. S. Barrite: J. Mater. Sci., 17 (1982), 732 .

12) I. Madariaga and I. Gutierrez: Acta Mater., 47 (1999), 951

13) I. Madariaga: Ph.D Thesis, Univ. Navarra, San Sebastian, Spain, (1999).
14) M. Diaz-Fuentes, I. Madariaga and I. Gutierrez: Proc. J. J. Jonas Symposium on Thermomechanical Processing of SteelsCOM'2000, Met. Soc., Montreal, Canada, (2000), 489.

15) A. J. DeArdo: Mater. Sci. Forum, 426-432 (2003), 49.

16) H. K. D. H. Bhadeshia: Bainite in Steels, 2nd Ed., Institute of Materials, London, (2001), 206.

17) J. Talonen, P. Nenonen, G. Pape and H. Hänninen: Metall. Mater. Trans. A, 36A (2005), 421. 